\title{
EXTENSION OF OPERATIONAL LIFE-TIME OF WWER- 440/213 TYPE UNITS AT PAKS NUCLEAR POWER PLANT
}

\author{
TAMÁS JÁNOS KATONA*, SÁNDOR RÁTKAI \\ Nuclear Power Plant Paks \\ 7031, Paks, P.O. Box. 71, Hungary \\ "Corresponding author. E-mail : katonat@npp.hu
}

Received April 10, 2008

\begin{abstract}
Operational license of WWER-440/213 units at Paks NPP, Hungary is limited to the design lifetime of 30 years. Prolongation by additional 20 years of the operational lifetime is feasible. Moreover, enhancement of the reactor thermal power by $8 \%$ will increase both the net power output and the competitiveness of the plant. Paks NPP is a pioneer considering the power up-rate and preparation of long-term operation of WWER-440/213 design. Systematic preparatory work for longterm operation of Paks NPP has been started in 2000. A regulatory framework and a comprehensive engineering practice have been developed. According to the authors view, creation of a gapless engineering system via consequent application of best practices, and feed-back of experiences together with proper consideration of WWER-440/V213 features are the decisive elements of ensuring the safety of long-term operation. That systematic engineering approach is in the focus of recent paper. Key elements of justification and measures for ensuring the safety of long-term operation of Paks NPP WWER-440/213 units are identified and discussed. These are the assessment of plant condition and review of adequacy of ageing management programmes, also the review, validation and reconstitution of time limited ageing analyses as core tasks of licence renewal.
\end{abstract}

KEYWORDS : Long-Term Operation, Power Up-Rate, Time Limited Ageing Analyses, Ageing Management, WWER-440/213

\section{INTRODUCTION}

The four WWER-440/213 units at Paks NPP, Fiungary are approaching to their last decades of licensed and designed term of operation. Design life-time of WWER$440 / 213$ type reactors/plants is 30 years and the operational licence had been limited to that term. Detailed feasibility study demonstrates the possibility of extension of operational lifetime by additional 20 years, thanks to operational and maintenance practice, and robustness of design of the structures and components. Enhancement of the reactor thermal power by $8 \%$ will increase the net power output (from $460 \mathrm{MWe}$ to $\cong 500 \mathrm{MWe}$ ), consequently, it improves the competitiveness of the plant and makes the long-tem operation (LTO) even more reasonable. Longterm operation of Paks NPP is widely supported by the public in Hungary. According to Hungarian regulations, a formal license renewal (LR) is required for prolongation of operation. However safe and economically reasonable prolongation of operation of Paks WWER-440/213 type plant and any other old vintage plans should be considered in broader context. It requires:

a) a comprehensive engineering practice, which integrates - up-to-date knowledge on ageing phenomena,
- vigilance through condition monitoring /ageing management,

- ability to recognise the unexpected phenomenon when it arises,

- a consequent application of best practices,

- feed-back of experiences,

- proper consideration of WWER-440/V213 features,

- graded approach in accordance with safety relevance and plant lifetime limiting character of the given structure/component and ageing process;

b) a regulatory framework for controlling the safety both in the act of licence renewal and continuously during the operation.

Consequent application of these attributes will result in a gapless system of plant practice, applied engineering tools, methodologies and regulatory control processes.

A "gapless" plant system/approach means:

- all systems, structures and components (SSCs) have to be covered by certain plant programme,

- all ageing processes have to be considered,

- all plant activities have to be considered, i.e. the routine activities should be integrated with those specific to LTO utilizing the synergy between them.

Above criteria are valid for the regulatory frame as well. 
Obviously, the value of the system outlined above does not originate in its scientific novelty rather than in creative use of proven knowledge/techniques for solution of plant ageing problems while finding balance between safety and economy of operation.

Description of the preparation of long-term operation and licence renewal of Paks NPP is given in [1] and [2]. In recent paper, systematic adaptation of principles outlined above is presented with the aim to show, that any particular practice of long-term operation should be tailor made taking into account the peculiarities of the plant design, national regulations and plant existing practice, and any particular practice could be adequate if it follows the basic principles above. From this point of view, key elements of ensuring the safety of long-term operation of Paks NPP are discussed.

\section{CONCEPT OF ENSURING SAFETY IN LONG- TERM}

\subsection{Regulatory Framework for Long-Term Operation}

In case of Hungary a gapless regulatory system for ensuring the plant safety in long-term means:

a) a regulatory framework should be in place for control of compliance with current licensing basis;

b) license renewal should focus on control of safety function of lifetime-limiting structures and components;

c) completeness and adequacy of plant activities with respect to a) and b) should be also controlled.

According to Hungarian regulations, compliance with Current Licensing Basis (CLB) is controlled via annual updating of Final Safety Analysis Report (FSAR) and the routine Regulatory inspections and approvals. The content of FSAR is similar to those required by U.S. NRC Regulatory Guide 1.70 (Rev. 3). The FSAR consist also the definition of design bases.

The periodic safety review (PSR) is a tool for overall assessment of plant safety. PSR is not a licensing tool, nevertheless limitations and conditions to the operational licence also safety upgrading measures might be defined on the basis of PSR. The scope of the review is very similar to those described by IAEA NS-G-2.10 Guideline.

According to Hungarian regulation the control of performance and safety functions shall be ensured by certain plant programme or justified by analysis (i.e. by time limited ageing analyses - TLAAs). Performance and function of passive long-lived structures and components should be ensured by ageing management programmes, while functioning of active systems should be tested during the operation. Performance of latter has to be ensured via maintenance under maintenance rule (MR), i.e. evaluation and assessment of the effectiveness of the maintenance along safety criteria, and/or via implementation of the programme for maintaining the environmental qualification (EQ). Plant may select and optimise the methods applied for particular SSCs, while the plant practice should be gapless, i.e. all SSCs and degradation mechanisms affecting the safety functions should be covered by the system. However, in case of structures and components of high safety relevance, regulation requires performance of dedicated ageing management programmes. In case of systems working in harsh environment dedicated programme for maintaining of environmental qualification is required. This corresponds to the principle of graded approach.

License renewal is an act when the regulatory authority is checking practically all licensing conditions with specific attention to the lifetime limits of the plant, i.e. condition, ageing management and expected lifetime of long-lived passive safety classified structures and components. This is very similar to the 10 CFR 54 license renewal rule of U.S. NRC.

However in Hungarian regulation some deviations exist compared with the U.S. rules of licence renewal. According to the principles outlined in the introduction, a snapshot-type picture of the condition and lifetime limits of long-lived passive safety classified structures and components does not guarantee that the plant programmes and activities are effective and cover all SSCs and degradation mechanisms. Therefore the plant has to prepare Programme of Long-term Operation (LTO Programme) and submit it for regulatory control not later than 4 years before expiration of the operational licence (in particular case of Paks NPP by the end of 2008).

The LTO Programme consist of results and conclusions of reviews of ageing management programmes (AMPs) and time limited ageing analyses (TLAAs) and the measures resulting from those reviews, as well as the assessment of effectiveness of other plant programmes, i.e. effectiveness of the implementation of maintenance rule, programme for $\mathrm{EQ}$, plans for condition dependent replacements and reconstructions, programme for ensuring the ability/knowledge of operational organisation. It means the regulation of LR builds a strong link between activities specific to LR and other plant processes, like knowledge management, reconstruction, solving of obsolescence issue.

Formal application for licence renewal has to be made one year before the licence expiring (in case of Unit 1 it has to be done by the end of 2011). In the application the experience of three years operation in accordance with LTO Programme has to be evaluated and assessed. It has to be demonstrated that the LTO Programme is effective, it ensures the safe operation and comparing with the observed trends the forecasts made for justification of the safety of extended operation remain valid.

The Hungarian regulatory frame might seem multiple redundant. However the relation between FSAR and PSR 
and LR is clear.

The plant safety and compliance with current licensing basis has to be demonstrated in the annually updated FSAR, while the long term tendencies (ageing, feedback of experiences, new scientific evidences, new requirements) affecting the plant safety have to be assessed in PRS every ten years. The first Periodic Safety Review of Paks NPP (1995-1999) resulted in a comprehensive safety upgrading programme of Paks NPP. Second PSR of Paks NPP has been completed in 2007 focus more on plant ageing. The subsequent PSRs will validate also the forecasts made for LR with respect to the efficiency of AMPs and statements on time-limited ageing analyses (TLAAs). The PSR and annual updating of FSAR contain complementary information, which is required and sufficient for demonstrating the safety at the moment and in long-term.

LR is focusing on the ageing and ageing management of long lived passive structures and components. However the programmes for maintaining the intended safety function of active systems and equipment shall be reviewed and their efficiency shall be assessed in the Licence Renewal Application.

LR results shall be used in augmentation of the FSAR with respect to ageing management, time limits set by ageing analyses, etc.

\subsection{Core Tasks of License Renewal}

Core tasks of the preparation of LTO are directly linked to the requirements of the re-licensing. It covers the following main tasks:

a) assessment of the plant status, review and demonstration of adequacy of plant ageing management programmes (AMPs);

b) review, validation and reconstitution of time limited ageing analyses (TLAAs).

c) development of the LTO Programme.

The first two above tasks are the known basic tasks for licence renewal. These represent the adaptations of 10 CFR 54. The technical content of these tasks also similar to those defined in $10 \mathrm{CFR} 54$. International experience summarised has been also used while performing these tasks, e.g. [3]. However there are essential deviations from the well-known way of performing review of AMPs and validation of the TLAAs. Technical reason of these deviations will be discussed below, demonstrating the creative way of adaptation of proven techniques to a plant with specific design features. LTO Programme represents a specific and essential element of the preparation of long-term operation and license renewal in case of Paks NPP, which will be discussed too.

\section{AGEING MANAGEMENT REVIEW}

\subsection{Definition of the Scope of AMPs}

Scope of ageing management programmes at Paks NPP has been derived from the scope of license renewal. As a regulatory process, licence renewal is focusing on plant safety. Therefore the scope of LR covers all safety classified structures, systems and components (SSCs), which have to perform intended safety function during all operational lifetime. Those non-safety SSCs have to be included into the scope, failure of which may inhibit/affect the safety functions.

From this total scope the passive long-lived nonreplaceable structures and components $(\mathrm{SCs})$ have to be selected, since these SCs limit the plant lifetime. These SCs might require ageing management since they are non replaceable. However, proper programmes have to be in place in a gapless system for ensuring the functions of screened out SSCs.

\subsection{Problems Related to WWER-440/213 Design}

Applying the scoping and screening principles outlined above, first essential peculiarity of WWER$440 / 213$ design is related to the extreme large number of safety classified SSCs. In case of Paks NPP the number of SSCs within Safety Classes 1-3 is over hundred thousand. The number of passive, long-lived of SCs is also very large. It could be explained by the six-loop design and evolutionary character of the development of the WWER-440/213 type. The other cause of the large number of safety classified items is the deterministic way of classification, which classifies obligatorily large number of SSCs with apparently marginal contribution to core melt frequency.

After screening out the active and short lived systems, approximately 35000 mechanical, 6500 electrical and 2000 structural SCs have been identified to be in scope. This magnitude of the scope multiplies all the ageing management effort of the plant and also the volume of the reviews for LR. Therefore methods should be applied for reasonable management of this large scope, e.g.:

- careful structuring is required for effective organisation of ageing management;

- proper IT tools have to be developed for support of organisation of ageing management and dealing with information related to condition of the SCs.

The IT system developed for AM and LR support had been already reported in [4]. Here the structuring and organisation of AMPs will be discussed only.

\subsection{Structuring, Organizing the Ageing Management Activity}

Here the graded approach should be applied according to the safety relevance of the given structure or component and plant life-time limiting character of the given ageing mechanisms. Accordingly, SCs have been separated into two categories: 
- highly important from safety point of view items with complex features and ageing mechanisms;

- items, e.g. pipelines, pipe elements (elbows, T-pieces), valves, heat exchangers, which have the same type, safety class, identical design features, materials, operating circumstances, dominating ageing mechanism could be grouped into commodity groups and for each commodity group a designated AMPs should be implemented.

The highly important SCs like reactor pressure vessel (RPV) together with internals, components of main circulating loop (SCs of Safety Class 1 and some SCs of Class 2) should have dedicated AMPs, which are composed from several programmes each of them is addressing one of the mechanism or critical location.

Considering the mechanical SCs around 150 commodity groups have been identified. The number of structural commodities exceeds 25 .

Also the ageing management programmes have to be structured in a hierarchy that allows better organisation of the plant activity. This could be illustrated on the example of building structures and structural components.

The WWER-440/213 design is very much differing from the usual architecture of PWRs. In case of Paks NPP practically all buildings, earth structures, etc. at the plant are within the scope. Most of these building structures are complex, and heterogeneous from the point of view of structural design, layout, manufacturing and construction of members, material composition and contact with environment.

In case of Paks NPP it would be difficult to adopt the AMPs described in GALL Report [5], where nine groups of building structures, seven groups of structural components are defined and ten ageing management programmes cover the whole scope. (They are: ASME BPV Code, Section XI, Subsections IWE, IWL and IWF, the leak-test programme in accordance with 10 CFR 50, APPENDIX J, a masonry wall programme, a generic Structures Monitoring Program under 10 CFR 50.65 MR, an inspection programme for water-control structures (in accordance with RG 1.127), a protective coating monitoring programme, and partly the water chemistry and boric acid corrosion programme.)

Therefore establishment of ageing management of structures, and structural components should be done according to following procedure:

a) development of basic (type A) AMPs:

- Identification of typical structural elements/members (commodities) from which the plant building structures are built up, according to design/type, material, manufacturing/construction and environment, (e.g. reinforced concrete columns, walls in air inside the buildings);

- Identification of ageing mechanisms for all commodities;
- Development of AMPs for each of commodities. These programmes are generic in sense that they might be applied for the same structural commodity in any building.

b) Development of (type B) AMPs for complex structures/ buildings:

- Identification of complex structures, buildings or parts of building which form an entity from ageing management point of view;

- Identification of basic AMPs to be applied in case of a given complex structure;

- Definition of conditions of application of basic AMPs, e.g. critical locations in particular building, criteria of acceptability of ageing effects for a particular member in particular building;

- Definition of schedule, logistics of application of basic AMPs for given complex structure. This is necessary since the accessibility of buildings should be taken into account as well as the particular requirements for the application of the basic AMPs for the given structure.

The type A programmes have been developed for commodities below:

\begin{tabular}{ll}
\hline - Foundations & - Reactor support structure \\
- RC-structural members & - High temperature concrete \\
- Equipment foundations & - Water steel structures \\
- Prefabricated panels & - Water RC structures \\
- Masonry walls & - Earth structures \\
- Steel-structures & - Cable and pipe supports \\
- SS-liners programme & - Cable and pipe penetrations \\
- Main building settlement & - Support structures of cabinets \\
- Building movement & - Doors and hatches \\
- Corrosion in boric acid environment & - Paintings and coatings \\
- Liners (C-steel) & - Fire protection structures \\
- Leak-tightness tests & - Sealing's and isolation \\
\hline
\end{tabular}

Using the type A programmes for specific structures (commodities) 30 programmes of type B have been composed which covers all plant building structures.

It is obvious the hierarchical structure of the AMPs is plant specific. The established hierarchy of the ageing management programmes demonstrates a real adaptation of best international practice to WWER-440/213 instead of copy-paste. In the same time, the identified ageing mechanisms, and other elements of an adequate ageing management programmes are in accordance with international practice $[3,5]$. 


\section{REVIEW AND VALIDATION OF TIME-LIMITED AGEING ANALYSES}

Review and validation of TLAAs is an essential element of the justification of licence renewal. This task seems to be rather complex in case of Paks NPP, similar to any other WWER-440/213 plant. The issue is related to the availability of design base information and incompleteness of the delivered design documentation. Although Paks NPP performed a design base (DB) reconstitution project, part of the original design assumptions, inputs and the design conditions remained unknown. Often the final results of the analyses are known only; in some cases the analyses are presumably obsolete. It had been recognised that the recovery and review of original TLAAs would be insufficient for justification of licence renewal because of essential changes in regulatory requirements affecting also the design bases. The TLAAs have to be reviewed and verified for most important SCs by control calculations using state-of-the-art methods. In many cases the time limited ageing analyses have to be newly performed in accordance with the recent requirements and guidelines. Review, validation and reconstitution of TLAAs implicate also verification of existing strength calculations for selected most important SCs.

Review, validation and reconstitution of TLAAs for LR of Paks NPP have been reported in [6]. Most important aspects of this key issue will be discussed here. These are related to the scope time limited ageing analyses, their methodology and peculiarities of the adaptation of ASME BPVC.

First step of the tasks is the definition of the scope of SCs to be examined and scope of analyses to be performed. According to Hungarian regulation this scope shall cover the SCs of Safety Class 1 and 2, which includes the reactor pressure vessel (RPV), steam generators (SG), pressurizer vessel, cases of the main circulating pumps and the main gate valves, other Safety Class 1 and 2 pipes, vessels, pumps, heat exchangers and valves. Considering the amount of required analyses, the fatigue analysis to be reviewed or newly performed shall cover the Safety Class 1 and 2 components. Analysis of the reactor pressure vessel includes PTS calculation, and developing new $\mathrm{p}$ - $\mathrm{T}$ curves. Where appropriate the thermal stratification has to be analysed. A specific requirement is the checking whether a ten years margin exist above the 50 years of operation. Obviously, the scope of analyses required by Hungarian regulation exceeds the scope of regular review of TLAAs performed for licence renewal.

Hungarian regulations require application of state-ofthe-art methods, codes and standards while performing the time limiting ageing analyses. ASME Boiler \& Pressure Vessel Code, Section III: Rules for Construction of Nuclear Facility Components, edition 2001 (hereafter,
ASME BPVC III) had been selected for the reconstitution of TLAAs and associated strength verification. Use of ASME code is a generic decision of the Paks NPP. Currently the ISI programs at Paks NPP are under comprehensive review in order to modify them to meet the requirements of the ASME BPVC Section XI and ensure the proper ageing management (see [7]).

The code selection requires understanding of both the Russian (Soviet) design standards and the ASME code. Different studies had been performed for ensuring the adequacy of ASME implementation for WWER-440/213. A comprehensive and very detailed Methodology and Criteria Document has been developed, which describes the routine application of ASME BPVC III and also provides additional instructions regarding specific aspects of strength calculations and validation/reconstitution of TLAAs.

It is obvious that unavoidable deviations shall be between a routine ASME BPVC III analysis and recent methodology of reconstitution of TLAAs for Paks NPP. These deviations are caused either by specific regulatory environment or by technical peculiarities of the WWER$440 / 213$ units.

An important issue of the ASME BPVC III application is related to definition of material properties. With this respect the manufacturer's national and industrial standards, designers or manufacturer's technical specifications and former Hungarian regulatory rules related to materials, welding and quality assurance shall be considered as relevant. If the relevant information could not be recovered from the supplied documentation, the Russian PNAE G-7-002-86 [8] code shall be applied.

Materials of the equipment of WWER-440/213 within the scope of fatigue analyses are carbon steels, low-alloy steels (ST20, 22K, 15H2MFA, 18H2MFA) and stainless-steels $(08 \mathrm{H} 18 \mathrm{~N} 10 \mathrm{~T}, 08 \mathrm{H} 18 \mathrm{~N} 12 \mathrm{~T})$. From the point of view of reconstitution of TLAAs the fatigue curves have very important role. Consideration has been made for the proper selection of fatigue curves. Applicability of material-specific fatigue curves specified by Russian code PNAE has been justified. For this reason the empirical, theoretical background of fatigue curves has been analysed. Based on these studies the fatigue curves to be applied in the analyses are the material-specific curves in PNAE. Impact of the environment on the fatigue is accounted by adaptation of current U.S. practice.

Reconstitution of TLAAs has specific aspects with respect to the brittle fracture analysis. It has to be performed for all critical cross-sections of the equipment according to the Code. However, in case of already operating pumps and valves, impact test results for materials are not available. In this case analysis has to be performed according to the method and procedure developed in frame of VERLIFE Project [9].

Change of transition temperature due to ageing might 
be calculated according to either PNAE or VERLIFE methodology. Considering the time limit of operation of the RPV, neutron irradiation damage, thermal ageing and low-cycle fatigue decreasing the fracture toughness of the RPV materials should be analysed. According to extensive studies performed by designer and Hungarian experts the pressurised thermal shock (PTS) is the most critical lifetime limiting event for RPV. Effect caused by neutron irradiation is dominating near the core. This part of RPV is most sensitive from the point of view of brittle crack initiation and propagation. At other parts of RPV, the stresses might be much higher and the neuron fluence much lower than in the area of beltline region. Such locations are the nozzles and their vicinity, the vicinity of the supporting flange and weld $3 / 5$. According to the studies performed the vicinity of the weld $8 / 9$ is not a critical location for PTS, nevertheless it is included into the analysis. The reactor main flange and its vicinity not exposed to high neutron radiation, consequently it is not critical from point of view of PTS. The same is valid for RPV head and the nozzles on it. These parts of RPV are not exposed to high neutron radiation and the stresses from internal pressure are considerably lower than in the nozzle region. Deterministic methodology of PTS analysis is given and prescribed in dedicated Hungarian regulatory guidelines.

With respect of RPV safety the LTO Programme includes management of RPV properties of aged structural materials, examination of further surveillance specimens, evaluation of expected effects of the measures affecting integrity (heating of coolant in emergency core cooling system, etc.).

Ageing due to fatigue affects the components of RPV in different extent. The designer and the manufacturer performed the basic fatigue analyses for the RPV critical components. In the frame of preparation of LR these analyses will be renewed taking into account the design base conditions. However, in order to determine time limit of operation of RPV and justification of long-term operation ( 50 years), it is necessary to account all effects of ageing, i.e. elements critical for PTS have to be checked also for fatigue and the elements critical for fatigue must be reviewed also for PTS.

In the frame of the TLAA reconstitution the critical brittle fracture temperature $(\mathrm{Tk})$ of the aged condition of the reactor pressure vessel materials has been re-evaluated. The value of neutron fluence in the characteristic points of the capsule assemblies participating in the surveillance programme as well as the values of the relevant neutron fluence distributions in the critical cross sections of the reactor pressure vessels regarding the base material and the weld material of the 5/6 weld, for the 60th and 50th years of reactor operation should be considered, presuming $108 \%$ and $100 \%$ power rates. The effects from the reactor thermal power up-rate are accounted here.

If it is necessary, modification of in-service-inspection programmes have to be identified and developed for management of aging during the period of extended operation on the basis of review, validation and reconstitution of TLAAs.

\section{LTO PROGRAMME}

\subsection{Development, Implementation and Evaluation of the LTO Programme}

Development, implementation and subsequent evaluation of a programme for long-term operation are an essential element in Hungarian practice. The function of passive long-lived non replaceable $\mathrm{SCs}$ is ensured by AMPs and justified by re-validated for extended operational lifetime TLAAs. Review of AMPs and TLAAs, also the evaluation and assessment of effectiveness of other plant programmes resulted in measures for amendment of ongoing plant practice. However, in a gapless system, proper programmes have to be in place for ensuring the functions all of SSCs (maintenance under maintenance rule, programme for $\mathrm{EQ}$, condition dependent, scheduled replacements, reconstructions).

LTO Programme consists continuation of qualified for adequate programmes, development of new or amendment some of existing programmes. All these measures should be integrated into an overall plant life management programme, which covers also the nonsafety classified SSCs and ensures all resources and conditions for operation and functioning of the operating company.

Paks NPP considers LTO Programme as an overall strategic programme which determines all areas of activity of operational company, e.g. human resource management, knowledge management. It demonstrates the plant commitment. After three years of operation in accordance with the LTO programme, experience should be evaluated, assessed and the findings have to be summarised in the Application for licence renewal. Besides of the results of the review of AMPs and validation of TLAAs these finding will demonstrate the safety and reasonability of long-term operation.

\subsection{Synergy Between Plant Processes}

LTO Programme establishes strong link between all activities of operating company. Proper management of the implementation will use the synergy between these activities.

Paks NPP performed a comprehensive safety upgrading programme, which required essential hardware modifications. Thanks to this the core damage frequency has been decreased up-to the level of $\sim 10^{-5} / \mathrm{a}$. Safety upgrading was an unavoidable precondition of the decision for LTO. Safety and plant commitment are the most important aspect of public acceptance. 
Safety upgrading caused direct or implicit technical benefit. The safety upgrading modifications impacted the most important safety systems. Due to these modifications the safety systems or their essential parts had been practically renewed, reconstructed. Consequently large part of safety systems is not aged. In some cases safety upgrading measures have direct influence on the lifetime limiting processes. For example, the new relief valves installed on the pressurizer provide the possibility of the reactor over-pressurisation protection in cold state, i.e. it eliminates the danger of brittle fracture of the reactor vessel.

The power will be up-rated by utilisation of modernised fuel. Practically the enthalpy of the coolant at the reactor outlet is increased only. Implementation of certain, relatively simple modifications also needed, e.g. modernisation of the primary pressure control system and of core monitoring system, replacement of the impellers of Main Circulating Pumps (MCP) on some units. The potential interrelation of the power up-rate on LTO programme is threefold: Power up-rate may cause in some cases/transients higher parameters. However it should not have an adverse effect on the lifetime expectations of critical components. Therefore the conditions of operation at up-rated power level have been taken into account while reviewing the TLAAs. Due to modifications the operation will be smoother, or some ageing problems will be solved (cracking of the impellers of MCP). Power up-rate has a positive impact on the economic viability of long-term operation.

Some modifications implemented during last ten years had been targeted to improvement of the operation reliability and cost effectiveness of power generation. Examples for that are: replacement of main turbine condensers, reconstruction of high pressure pre-heaters, etc. The replacement the main turbine condenser, which was motivated also by economic considerations, has an essential impact on the lifetime of the steam-generators. Steam generators are practically not replaceable in case of WWER-440/213 type units therefore the steam generator ageing is limiting the plant lifetime. The dominant ageing mechanism is the steam generator heatexchange tube stress corrosion. The new condensers with stainless steel tubing are leak-tight; they allowed the introduction of the high $\mathrm{pH}$ water regime in the secondary circuit providing better operational condition for components of the feed water system and for the steam generators as well. A $100 \%$ inspection of all steam generators shows that the new condensers and the high $\mathrm{pH}$ in the secondary circuit will improve the operating conditions of steam generator tubes, less corrosion and erosion products will be deposited on their surface. In addition higher leak-tightness of the condenser decreases intrusion of impurities from condenser cooling water. According to recent assessment the steam generators might be operated the target time of 50 years.

\section{CONCLUSIONS}

In Hungary a comprehensive regulatory framework and comprehensive plant system have been developed for ensuring the safety of long-term operation of WWER-440/213 type plant at Paks.

This followed the principles outlined in the paper. Applying these principles a gapless system could be established which ensures that any SSCs will be covered by some of the plant programmes, and within the frame of LTO Programme all conditions of proper operation will be ensured in line with basic criterion of completeness of plant practice.

Best international practice and state-of-the-art methodologies have been applied while performing the particular tasks for preparation and justification of longterm operation and licence renewal. However, as it has been demonstrated, any good examples and experiences should be adapted in creative way taking into account the design features, national regulations, and existing plant practice.

This way the strategy of Paks NPP to operate safely as long as possible and economically reasonable at higher power level will be ensured.

\section{REFERENCES}

[ 1 ] Katona T.J., Jánosiné Bíró A., Rátkai S. and Ferenczi Z. (2005). „Key Elements of the Ageing Management of the WWER-440/213 type Nuclear Power Plants" 18th International Conference on Structural Mechanics in Reactor Technology (SMiRT 18), Beijing, China, August 7-12, 2005.

[2] T. Katona, S. Rátkai, Key Elements of Long Term Operation of WWER-440/213 Units at Paks NPP, paper IAEA-CN-155-003, Second International Symposium on Nuclear Power Plant Life Management, Shanghai, China 15-18 October 2007.

[ 3 ] Katona Tamás János, Role of the Periodic Safety Review and the Updated Final Safety Analysis Report in Ensuring of the Safety of Long-Term Operation of Paks NPP, paper presented at the Technical Meeting on Experience of Member States in Implementing Periodic safety Reviews of NPPs, Vienna, 27-29 October 2004.

[4] Safety Aspects of Long Term Operation of Water Moderated Reactors, IAEA-EBP-SALTO, International Atomic Energy Agency, Vienna, July 2007.

[5] Dr. Tamás Katona, Jánosiné Bíró Ágnes, Dr. László Czibolya, Sándor Rátkai: Aging Management Database at the VVER-440/213 Units of Paks NPP, 18th International Conference on Structural Mechanics in Reactor Technology (SMiRT 18), Beijing, China, August 7-12, 2005, Post Conference Seminar 12.

[6] Generic Aging Lessons Learned (GALL) Report, NUREG -1801 , U.S. Nuclear Regulatory Commission, Washington, DC 20555-0001, July 2001.

[ 7 ] Trampus P., Jánosi B. Á., Pammer Z., Rátkai S., Szabó D. and Somogyi G. (2006). Adaptation of ASME requirements for ISI/NDE at Paks NPP" 5th International Conference on NDE in Relation to Structural Integrity for Nuclear and 
KATONA et al., Extension of Operational Life-Time of WWER-440/213 Type Units at Paks Nuclear Power Plant

Pressurised Components, San Diego, 10-12 May 2006.

[8] PNAE G-7-002-86: Strength analysis norms of equipment and pipelines of nuclear power facilities, 1990 (in Russian).
[9] VERLIFE Unified Procedure for Lifetime Assessment of Components and Piping in WWER NPPs. Final Version, 2003, EC. 